\title{
Paradoxical worsening of hypoxemia in a patient treated by noninvasive positive pressure ventilation for obesity hypoventilation syndrome with concomitant obstructive sleep apnea: a case report
}

Carole de Picciotto ${ }^{1}$, Coraline Duménil ${ }^{2}$, Olivier Auzel ${ }^{3}$, Violaine Giraud ${ }^{2}$ and Marcel Bonay ${ }^{1,4,5^{*}}$ (D)

\begin{abstract}
Background: Noninvasive positive pressure ventilation is frequently prescribed to obese patients with obstructive sleep apnea syndrome and obesity hypoventilation syndrome. However, mechanical ventilation with a positive end-expiratory pressure can induce or worsen a right-to-left shunt through a patent foramen ovale associated with systemic hypoxemia. Thus, in obese patients treated with noninvasive positive pressure ventilation, a paradoxical worsening of hypoxemia may reveal the existence of a patent foramen ovale.

Case presentation: A 50-year-old African woman was referred to our sleep center for severe obstructive sleep apnea syndrome and obesity hypoventilation syndrome. Because she had alveolar hypoventilation and had failed previous obstructive sleep apnea syndrome therapy, noninvasive positive pressure ventilation was started. In May 2015, she had a normal residual apnea/hypopnea index calculated by the ventilator software with no hypoventilation. Six months later, severe hypoxemia without hypercapnia was noted. Contrast transthoracic echocardiography showed right-to-left shunt through a patent foramen ovale. This finding prompted a decrease in expiratory and inspiratory positive airway pressures, after which the ventilator software recorded a normal residual apnea/hypopnea index and the blood gas values improved.

Conclusion: Noninvasive positive pressure ventilation therapy for combined obstructive sleep apnea syndrome and obesity hypoventilation syndrome must be monitored by arterial blood gas measurements, both to reassess the hypercapnia and to look for worsening hypoxemia due to a patent foramen ovale.
\end{abstract}

Keywords: Hypoxemia, Obstructive sleep apnea, Hypoventilation, Noninvasive ventilation, Obesity

\footnotetext{
* Correspondence: marcel.bonay@inserm.fr

${ }^{1}$ Service de Physiologie-Explorations Fonctionnelles, Hôpital Ambroise Paré, Assistance Publique-Hôpitaux de Paris, Boulogne, France

${ }^{4}$ Unité Inserm U1179, laboratoire de physiologie TITAN, UFR des Sciences de la Santé Simone Veil, Université de Versailles St Quentin (UVSQ), Montigny le Bretonneux, France

Full list of author information is available at the end of the article
} 


\section{Background}

The foramen ovale is a congenital opening between the two cardiac atria that usually closes shortly after birth but may remain patent. Thus, a patent foramen ovale (PFO) is found at autopsy in 20 to $34 \%$ of the general population [1]. The PFO represents a channel through which unidirectional blood flow from the right venous blood to the left oxygenated arterial system may occur. The passage of blood from the venous blood into the left arterial blood without lung oxygenation is named right-to-left shunt. It may be associated with hypoxemia, defined in terms of reduced oxygen pressure in the systemic arterial blood $\left(\mathrm{PaO}_{2}\right)$, as detected by an arterial blood gas (ABG) measurement at rest.

Right atrial pressures are elevated in patients with pulmonary hypertension $(\mathrm{PH})$, which may be primary or secondary to another condition such as chronic obstructive pulmonary disease (COPD) or obstructive sleep apnea syndrome (OSAS) [2], and enhance the chance of a right-to-left intracardiac shunt through the foramen ovale. Of 48 patients with OSAS, 33 (69\%) had a PFO detectable by contrast transesophageal echocardiography (TEE), compared to only $4(17 \%)$ of 24 controls $(P<$ 0.0001) [3]. Systolic pulmonary artery pressure (sPAP) was significantly higher in the patients than in the controls. In the absence of right atrial pressure elevation, right-to-left shunt through the foramen ovale may occur intermittently, sometimes in relation to body position (platypnea-orthodeoxia syndrome). Right atrial pressures may rise abnormally in the absence of $\mathrm{PH}$, for instance during mechanical ventilation with a positive endexpiratory pressure (PEEP) of at least $10 \mathrm{~cm} \mathrm{H}_{2} \mathrm{O}$. In this situation, right-to-left shunt through the PFO worsens the systemic hypoxemia [4-6]. Furthermore, a peak inspiratory airway pressure of $20 \mathrm{~cm} \mathrm{H}_{2} \mathrm{O}$ has been shown to improve the TEE detection of PFO [7]. Finally, in a patient with tetralogy of Fallot and severe kyphoscoliosis, noninvasive ventilation paradoxically worsened the hypoxemia by increasing the right-to-left interventricular and right ventriculoatrial pressure gradients [8]. We are not aware of previous reports of paradoxical worsening of hypoxemia due to a right-to-left shunt through a PFO in a patient chronically treated by noninvasive positive pressure ventilation (NPPV) for obesity hypoventilation syndrome (OHS) with concomitant OSAS.

\section{Case presentation}

A 50-year-old African woman was referred to our sleep center for a combination of severe OSAS and OHS. She had a history of systemic hypertension treated since 2010, chronic systemic lupus erythematosus with cutaneous and joint manifestations, a positive serum anticardiolipin antibody test, and Sjögren's syndrome with lymphocytic interstitial lung disease diagnosed in 2009 and treated by an immunosuppressant and glucocorticoid until 2011.

Her body mass index was $35.6 \mathrm{~kg} / \mathrm{m}^{2}$. Consequently, in January 2015, she underwent respiratory polygraphy (CID 102 L; Cidelec, Angers, France) to look for OSAS. Her apnea/hypopnea index (AHI) was 37/hour, indicating severe OSAS. Obstructive hypopneas predominated (Fig. 1a). Total lung capacity and forced expiratory volume in one second/vital capacity (FEV1/VC) were normal but singlebreath diffusing capacity of the lungs for carbon monoxide (DLCO) was slightly decreased. ABG analysis evidenced hypoxemia and chronic hypercapnia: $\mathrm{PaO}_{2}, 78 \mathrm{mmHg}$; carbon dioxide pressure in the systemic arterial blood $\left(\mathrm{PaCO}_{2}\right), 48 \mathrm{mmHg}$; $\mathrm{HH}, 7.39$; calculated bicarbonate level, $29 \mathrm{mmoL} / \mathrm{L}$; and hemoglobin oxygen saturation, 94\%. The combination of obesity and alveolar hypoventilation in the absence of lung or neuromuscular disease established the diagnosis of OHS.

She had previously discontinued continuous positive airway pressure (CPAP) therapy due to discomfort with a feeling of suffocation. Given the alveolar hypoventilation, she was therefore started on NPPV (S9 VPAP; ResMed Corp., San Diego, CA, USA) in spontaneous timed (ST) mode, with an expiratory positive airway pressure (EPAP) of $7 \mathrm{~cm} \mathrm{H}_{2} \mathrm{O}$, an inspiratory positive airway pressure (IPAP) of $16 \mathrm{~cm} \mathrm{H}_{2} \mathrm{O}$, and a pressure support of $9 \mathrm{~cm}$ $\mathrm{H}_{2} \mathrm{O}$. In May 2015, the built-in ventilator software (ResScan) reported an AHI of 5.7/hour. Duration of ventilator use was 5 hours 18 minutes. During nocturnal NPPV, mean transcutaneous carbon dioxide $\left(\mathrm{PtcCO}_{2}\right)$ was $45 \mathrm{mmHg}$ and mean oxygen saturation was $95 \%$, indicating resolution of the hypoventilation. Diurnal ABG analysis confirmed this finding $\left(\mathrm{PaO}_{2}, 87 \mathrm{mmHg} \mathrm{PaCO}_{2}, 43\right.$ $\mathrm{mmHg}$; and $\mathrm{pH}, 7.45)$.

Polysomnography (Medatec; Ablis, France) during NPPV was performed in December 2015 because our patient reported sleeping poorly. The results showed excellent upper airway patency (AHI, 1/hour); periodic limb movements with an index of 16.9 /hour, resulting in sleep fragmentation with a microarousal/arousal index of 15/hour; and a mean oxygen saturation of $92.2 \%$.

In late December 2015, shortly after the polysomnography, she reported worsening exertional dyspnea. ABG analysis was performed to assess this symptom and as part of the routine monitoring of alveolar hypoventilation. Her hypoxemia had worsened $\left(\mathrm{PaO}_{2}, 53.7 \mathrm{mmHg}\right)$, whereas $\mathrm{PaCO}_{2}$ and $\mathrm{pH}$ were normal $(42.8 \mathrm{mmHg}$ and 7.43 respectively). She was admitted with transient nasal oxygenotherapy. Computed tomography pulmonary angiography showed dilatation of her pulmonary artery with no evidence of pulmonary embolism. During salinecontrast transthoracic echocardiography with and without Valsalva maneuvers, early passage of over 30 bubbles into the left side of her heart was noted, suggesting PFO (Fig. 2). 


\section{a \\ Respiratory events}

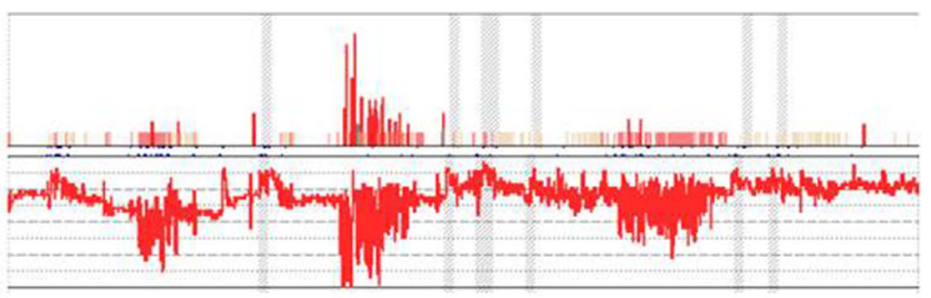

b

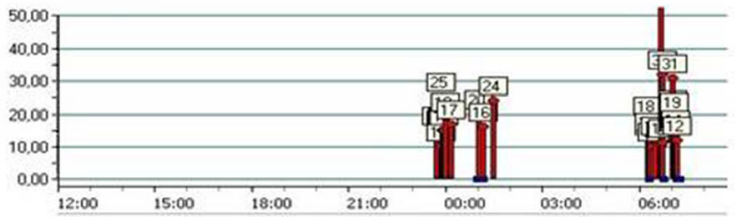

May 2015

Apnea

- Hypopnea

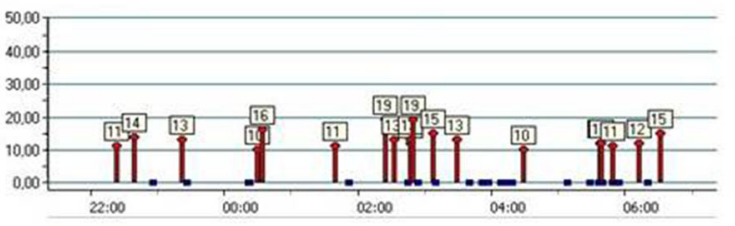

Dec 2015

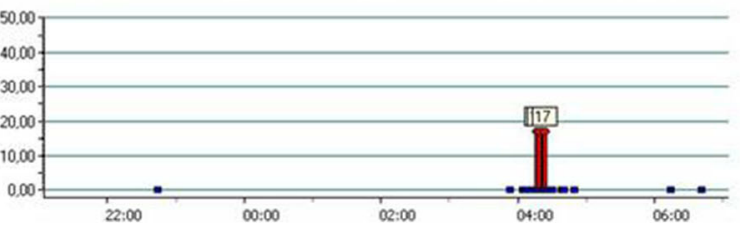

Aug 2016

Fig. 1 a Respiratory polygraphy. Top: Obstructive apneas are shown by solid red bars, central apneas by solid gray bars, obstructive hypopneas by red speckled bars, and indeterminate hypopneas by orange speckled bars. The height of the bars reflects the duration of the respiratory event. Bottom: Oxygen saturation by pulse oximetry. b Data from the ResMed ventilator software ResScan: obstructive apneas are in red and obstructive hypopneas in blue; the numbers above the lines are event durations in seconds. $\mathrm{SpO}_{2}$ oxygen saturation by pulse oximetry

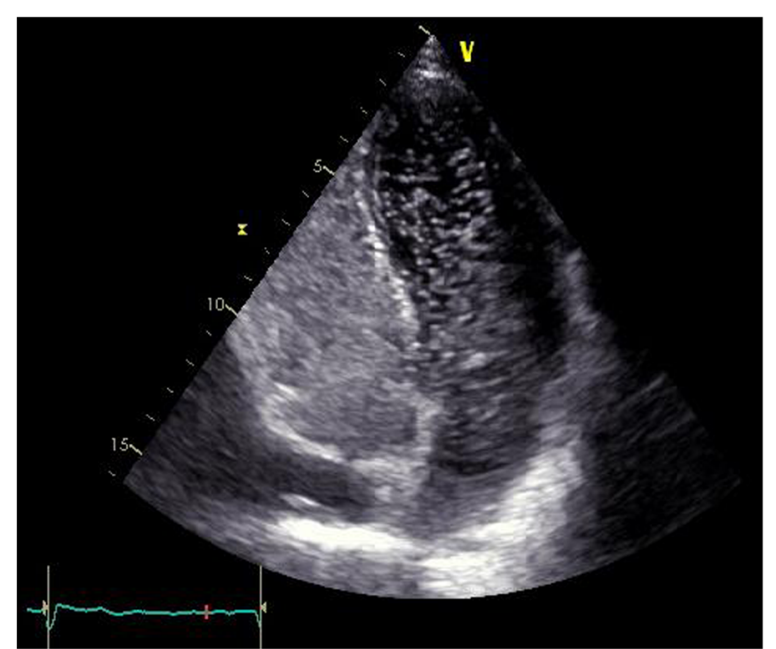

Fig. 2 Contrast-enhanced transthoracic echocardiography. Passage of microbubbles to the left atrium during the first three beats after right atrial opacification
Her left ventricular ejection fraction was normal and the estimated sPAP was $50 \mathrm{mmHg}$. Nasal oxygenotherapy was stopped after the diagnosis of PFO and she was monitored in the hospital for a few days, during which her pulse oximetry values improved, suggesting intermittent opening of the foramen ovale.

In January 2016, sPAP value was again estimated at $50 \mathrm{mmHg}$, confirming the diagnosis of $\mathrm{PH}$, which was ascribed to left-sided heart disease. The finding by computed tomography of smooth septal thickening in a perihilar and gravitational distribution prompted a diuretic challenge. After the treatment, transthoracic echocardiography showed normal sPAP (35 $\mathrm{mmHg}$ ) and left ventricular ejection fraction, confirming the diagnosis of pulmonary edema.

Given the right-to-left shunt through a PFO, the NPPV parameters were changed in January 2016: the EPAP was decreased to $6 \mathrm{~cm} \mathrm{H}_{2} \mathrm{O}$ and the IPAP to $12 \mathrm{~cm} \mathrm{H}_{2} \mathrm{O}$. In August 2016, the ventilator software reported a normal AHI of 3.4/hour (Fig. 1b) and ABG showed a mild hypercapnia and no hypoxemia $\left(\mathrm{PaO}_{2}, 85 \mathrm{mmHg}\right.$ and $\left.\mathrm{PaCO}_{2}, 45.7 \mathrm{mmHg}\right)$. These blood gas values have remained unchanged for several months (Table 1). 
Table 1 Time-course of arterial blood gas values and expiratory/inspiratory positive airway pressures used for noninvasive positive pressure ventilation

\begin{tabular}{|c|c|c|c|c|c|c|c|c|}
\hline & $\mathrm{PaO}_{2} \mathrm{mmHg}$ & $\mathrm{PaCO}_{2} \mathrm{mmHg}$ & Hemoglobin oxygen saturation \% & NPPV & Duration of NPPV use & EPAP $\mathrm{cm} \mathrm{H} \mathrm{H}_{2} \mathrm{O}$ & IPAP $\mathrm{cm} \mathrm{H} \mathrm{H}_{2} \mathrm{O}$ & $\overline{\mathrm{AHI}}$ \\
\hline January 2015 & 78.4 & 48 & 95.5 & 0 & I & / & / & 37 \\
\hline May 2015 & 87 & 43 & 97 & + & 5 hours 18 minutes & 7 & 16 & 5.7 \\
\hline December 2015 & 53.7 & 42.8 & 90 & + & 3 hours 30 minutes & 7 & 16 & 5 \\
\hline August 2016 & 85 & 45.7 & 96.7 & + & 4 hours 39 minutes & 6 & 12 & 3.4 \\
\hline
\end{tabular}

AHI apnea/hypopnea index, EPAP expiratory positive airway pressure, IPAP inspiratory positive airway pressure, NPPV noninvasive positive pressure ventilation, $\mathrm{PaCO}_{2}$ carbon dioxide pressure in the systemic arterial blood, $\mathrm{PaO}_{2}$ oxygen pressure in the systemic arterial blood

\section{Discussion}

That mechanical ventilation with PEEP can induce or worsen a right-to-left shunt through a PFO is well documented $[4,5]$. In contrast, to the best of our knowledge, a single study has assessed the hemodynamic effects of noninvasive ventilation in patients with $\mathrm{OHS}$, and it had only 30 patients [9]. Right ventricular overload was found in $43.3 \%$ of patients, that is, slightly above the 20 to $40 \%$ prevalence of $\mathrm{PH}$ reported in isolated OSAS [10, 11]. After 6 months of NPPV, there was a significant decrease in sPAP [9]. This result requires confirmation in larger studies.

In our patient, OHS and OSAS may have contributed to the $\mathrm{PH}$. The sPAP decline induced by diuretic therapy suggests left-sided heart disease. The mechanism by which PH secondary to left-sided heart disease may have contributed to induce right-to-left shunt through the PFO, leading to a paradoxical aggravation of the hypoxemia, remains unknown. In a patient who had OHS and OSAS with a history of unsuccessful NPPV, closure of the PFO dramatically improved the hypoxemic respiratory failure [12]. In our patient, NPPV probably further increased the right atrial pressure, reversing the pressure gradient between the two atria and inducing right-to-left shunt through the PFO. Furthermore, the $\mathrm{PaO}_{2}$ fluctuations during NPPV treatment in our patient were consistent with intermittent opening of the foramen ovale suggesting that the balance of pressures between the right side and the left side of her heart was very unsteady. It would have been interesting to perform sequential bubble tests in increasing EPAP and IPAP values (under adequate monitoring in an intensive care unit; ICU) to provide definite proof of our hypothesis, but we did not carry out this test because of ethical considerations.

\section{Conclusion}

In conclusion, NPPV therapy for combined OSAS and $\mathrm{OHS}$ requires $\mathrm{ABG}$ monitoring both to evaluate the course of the hypercapnia and to look for paradoxical worsening of the hypoxemia due to right-to-left shunt through a PFO, particularly as very high pressures may be needed to correct the hypoventilation.

\section{Abbreviations}

ABG: Arterial blood gas; AHI: Apnea/hypopnea index; COPD: Chronic obstructive pulmonary disease; CPAP: Continuous positive airway pressure;
DLCO: Diffusing capacity of the lungs for carbon monoxide; EPAP: Expiratory positive airway pressure; FEV1NC: Forced expiratory volume in one second/ vital capacity; ICU: Intensive care unit; IPAP: Inspiratory positive airway pressure; NPPV: Noninvasive positive pressure ventilation; OHS: Obesity hypoventilation syndrome; OSAS: Obstructive sleep apnea syndrome; $\mathrm{PaCO}_{2}$ : Carbon dioxide pressure in the systemic arterial blood; $\mathrm{PaO}_{2}$ : Oxygen pressure in the systemic arterial blood; PEEP: Positive end-expiratory pressure; PFO: Patent foramen ovale; PH: Pulmonary hypertension; $\mathrm{PtcCO}_{2}$ : Transcutaneous carbon dioxide; SPAP: Systolic pulmonary artery pressure; ST: Spontaneous timed;

TEE: Transesophageal echocardiography

\section{Acknowledgements}

We thank the patient who generously provided consent to publish her medical history to help other patients.

\section{Funding}

There was no funding for writing this article.

Availability of data and materials

All data are available in the electronic medical records of our hospital, accessible to the treating medical doctors.

\section{Authors' contributions}

$C d P, C D, V G$, and $M B$ analyzed and interpreted the patient data regarding the respiratory disease. $\mathrm{OA}$ analyzed and interpreted the patient data regarding the cardiovascular disease. CdP and MB were major contributors in writing the manuscript. All authors read and approved the final manuscript.

Ethics approval and consent to participate

Not applicable.

\section{Consent for publication}

Written informed consent was obtained from the patient for publication of this case report and any accompanying images. A copy of the written consent is available for review by the Editor-in-Chief of this journal.

\section{Competing interests}

The authors declare that they have no competing interests.

\section{Publisher's Note}

Springer Nature remains neutral with regard to jurisdictional claims in published maps and institutional affiliations.

\section{Author details}

${ }^{1}$ Service de Physiologie-Explorations Fonctionnelles, Hôpital Ambroise Paré, Assistance Publique-Hôpitaux de Paris, Boulogne, France. ${ }^{2}$ Service de Pneumologie, Hôpital Ambroise Paré, Assistance Publique-Hôpitaux de Paris, Boulogne, France. ${ }^{3}$ Service de Cardiologie, Hôpital Ambroise Paré, Assistance Publique-Hôpitaux de Paris, Boulogne, France. ${ }^{4}$ Unité Inserm U1179, laboratoire de physiologie TITAN, UFR des Sciences de la Santé Simone Veil, Université de Versailles St Quentin (UVSQ), Montigny le Bretonneux, France. ${ }^{5}$ Hôpital Ambroise Paré, 9 avenue Charles de Gaulle, 92104 Boulogne cedex, France. 
Received: 5 April 2017 Accepted: 19 July 2017

\section{Published online: 23 August 2017}

\section{References}

1. Hagen PT, Scholz DG, Edwards WD. Incidence and size of patent foramen ovale during the first 10 decades of life; an autopsy study of 965 normal hearts. Mayo Clin Proc. 1984;59:17-20.

2. Bancal C, Arnoult F, Krapf L, Bonay M. Patent foramen ovale and hypoxaemia with or without elevated right heart pressures. Rev Mal Respir. 2011;28:967-77.

3. Shanoudy H, Soliman A, Raggi P, Liu JW, Russell DC, Jarmukli NF. Prevalence of patent foramen ovale and its contribution to hypoxemia in patients with obstructive sleep apnea. Chest. 1998;113:91-6.

4. Cujec B, Polasek P, Mayers I, Johnson D. Positive end-expiratory pressure increases the right-to-left shunt in mechanically ventilated patients with patent foramen ovale. Ann Intern Med. 1993;119:887-94.

5. Pick RA, Handler JB, Murata GH, Friedman AS. The cardiovascular effect of positive end-expiratory pressure. Chest. 1982;82:345-50.

6. Lemaire F, Richalet JP, Carlet J, Brun-Buisson C, MacLean C. Postoperative hypoxemia due to opening of a patent foramen ovale confirmed by a right atrium-left atrium pressure gradient during mechanical ventilation. Anesthesiology. 1982;57:233-6.

7. Konstadt SN, Louie EK, Black S, Rao TL, Scanlon P. Intraoperative detection of patent foramen ovale by transesophageal echocardiography. Anesthesiology. 1991;74:212-6.

8. Jullien V , Benhamou M, Lanfranchi P, Perrin C. Increase in right-to-left intracardiac shunt with non-invasive ventilation. Rev Mal Respir. 2005; 22:321-3.

9. Castro-Añón O, Golpe R, Pérez-de-Llano LA, López González MJ, Escalona Velasquez EJ, Pérez FR. Haemodynamic effects of non-invasive ventilation in patients with obesity-hypoventilation syndrome. Respirology. 2012;17:1269-74.

10. Bady E, Achkar A, Pascal S, Orvoen-Frija E, Laaban JP. Pulmonary arterial hypertension in patients with sleep apnoea syndrome. Thorax. 2000;55:934-9.

11. Sajkov D, Wang T, Saunders NA, Bune AJ, Neill AM, Douglas MR. Daytime pulmonary hemodynamics in patients with obstructive sleep apnea without lung disease. Am J Respir Crit Care Med. 1999;159:1518-26.

12. Mehrotra AK, Cork DP, Weiss SA, Shah AP. Dramatic improvement in hypoxemic respiratory failure after patent foramen ovale closure in a patient with obesity hypoventilation syndrome. Cardiovasc Revasc Med. 2012;13:295-7.

\section{Submit your next manuscript to BioMed Central and we will help you at every step:}

- We accept pre-submission inquiries

- Our selector tool helps you to find the most relevant journal

- We provide round the clock customer support

- Convenient online submission

- Thorough peer review

- Inclusion in PubMed and all major indexing services

- Maximum visibility for your research

Submit your manuscript at www.biomedcentral.com/submit
Biomed Central 